University of Wollongong

Research Online

Faculty of Engineering and Information

Faculty of Engineering and Information

Sciences - Papers: Part A

Sciences

2012

\title{
Finite element analysis of consolidation behavior of composite soft ground
}

S Horpibulsuk

Suranaree University of Technology,Suranaree University of Technology, suksun@g.sut.ac.th

A Chinkulkijniwat

Suranaree University of Technology,Suranaree University of Technology

A Cholaphatsron

Suranaree University of Technology

J Suebsuk

Suranaree University of Technology, j.suebsuk@gmail.com

M D. Liu

University of Wollongong, martindl@uow.edu.au

Follow this and additional works at: https://ro.uow.edu.au/eispapers

Part of the Engineering Commons, and the Science and Technology Studies Commons

Research Online is the open access institutional repository for the University of Wollongong. For further information contact the UOW Library: research-pubs@uow.edu.au 


\title{
Finite element analysis of consolidation behavior of composite soft ground
}

\begin{abstract}
Columnar inclusion is one of the effective and widely used methods for improving engineering properties of soft clay ground. This paper investigates the consolidation behavior of composite soft clay ground using both physical model tests under an axial-symmetry condition and finite element simulations using the PLAXIS 2D program. Because the soil-cement column enhances the yield stress and stiffness of the composite ground, the composite ground is in an over-consolidated state under the applied vertical applied stresses. At this state, the rate of consolidation is rapid due to a high coefficient of consolidation. The consolidation of the composite ground is mainly controlled by the area ratio, the ratio of the diameter of the soil-cement column to the diameter of the composite ground, a. As the area ratio increases, the rate of consolidation increases and the final settlement decreases.
\end{abstract}

\section{Keywords}

soft, composite, behavior, consolidation, ground, analysis, finite, element

Disciplines

Engineering | Science and Technology Studies

\section{Publication Details}

Horpibulsuk, S., Chinkulkijniwat, A., Cholaphatsron, A., Suebsuk, J. \& Liu, M. D. (2012). Finite element analysis of consolidation behavior of composite soft ground. GeoCongress 2012 (pp. 940-947). 
Finite Element Analysis of Consolidation Behavior of Composite Soft Ground

\author{
S. Horpibulsuk ${ }^{1}$, A. Chinkulkijnwat ${ }^{2}$, A. Cholaphatsron ${ }^{3}$, J. Suebsuk ${ }^{4}$ and M. D. Liu ${ }^{5}$ \\ ${ }^{1,2,3}$ School of Civil Engineering, Suranaree University of Technology, 111 University \\ Avenue, Muang District, Nakhon Ratchasima 30000, Thailand; email: \\ suksun@g.sut.ac.th \\ ${ }^{4}$ Department of Civil Engineering, Rajamangala University of Technology Isan, \\ Muang District, Nakhon Ratchasima 30000, Thailand; email: jirayut.su@rmuti.ac.th \\ ${ }^{5}$ Faculty of Engineering, University of Wollongong, NSW 2522, Australia; email: \\ martin@uow.edu.au
}

\begin{abstract}
Columnar inclusion is one of the effective and widely used methods for improving engineering properties of soft clay ground. This paper investigates the consolidation behavior of composite soft clay ground using both physical model tests under an axial-symmetry condition and finite element simulations using the PLAXIS 2D program. Because the soil-cement column enhances the yield stress and stiffness of the composite ground, the composite ground is in an over-consolidated state under the applied vertical applied stresses. At this state, the rate of consolidation is rapid due to a high coefficient of consolidation. The consolidation of the composite ground is mainly controlled by the area ratio, the ratio of the diameter of the soil-cement column to the diameter of the composite ground, $a$. As the area ratio increases, the rate of consolidation increases and the final settlement decreases.
\end{abstract}

\title{
INTRODUCTION
}

The method of mixing cement slurry or powder into soft ground (deep mixing) to create soil-cement columns is widely used to improve the engineering properties (shear strength and compressibility) of thick deposits of soft ground. Studies on the prediction of the engineering performance of soil-cement column improved ground have become attractive to both practitioners and researchers in Asia. Most of the available studies related to the deep mixing method have been confined to the strength and the overall stiffness of the soil-cement columns (Kawasaki et al., 1981; Kamaluddin and Balasubramaniam, 1995; Porbaha et al., 2001; Miura et al. , 2001; Horpibulsuk et al., 2004a, b; 2005; 2011a and b). The effect of the field mixing parameters, such as installation rate, water/cement ratio and rate of rotation on the strength development of soil-cement columns were investigated by Nishida et al. (1996) and Horpibulsuk et al. (2004c and 2011b). Based on the available compression and shear test results, many constitutive models were developed to describe the engineering behavior of cemented clay (Kasama et al., 2000; Horpibulsuk et al., 2010; Suebsuk et al., 2010 and 2011 etc).

Even though the understanding of the consolidation behavior of composite ground is significant for determining the final settlement and rate of settlement, the studies on this topic are very limited. This paper aims to illustrate the consolidation 
mechanism of the composite ground. Both laboratory tests on model composite ground and numerical simulations were performed for this objective. The laboratory tests were carried out in different conditions of the applied vertical stress and area ratio, which is the ratio of the soil-cement column diameter to the composite ground diameter. Numerical simulations were performed using the PLAXIS program.

\section{SOIL SAMPLE AND PHYSICAL MODEL}

The soil sample was soft Bangkok clay collected from the Chidlom district, Bangkok at a depth of three meters. The clay was composed of $11 \%$ sand, $17 \%$ silt and $72 \%$ clay. The natural water content was $80 \%$ and the specific gravity was 2.68 . The liquid and plastic limits were $81 \%$ and $34 \%$, respectively.

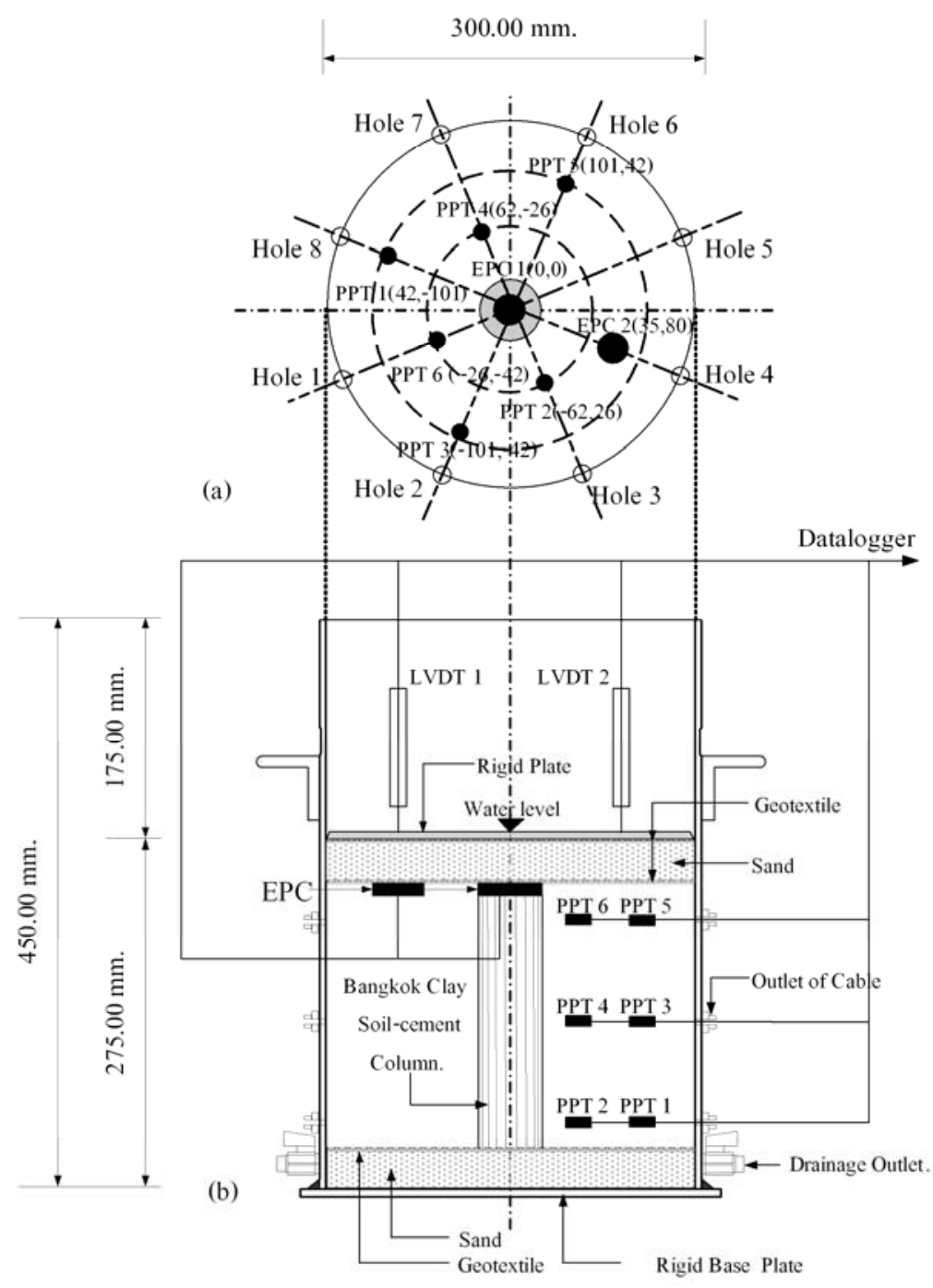

Figure 1. Location of instruments in the physical model: (a) plan view of positions of various transducers; (b) side view. 
A cylindrical stainless steel mold $300 \mathrm{~mm}$ in diameter and $450 \mathrm{~mm}$ in height was used for the experimental research as shown in Figure 1. The soil-cement columns with $5 \mathrm{~cm}$ and $10 \mathrm{~cm}$ diameters were installed in the middle of the mold. This physical model test simulated a composite foundation where soil-cement columns are installed vertically in a triangular or square pattern at the same spacing in a horizontal clay layer and are subjected to uniform vertical fill loading over an extensive area (Yin and Fang, 2006). The consolidation around a soil-cement column was approximately axisymmetrical with an equivalent diameter, at the boundary of which lateral displacement was not permitted. The concept of the equivalent diameter is first introduced by Barron et al. (1948) to study the consolidation behavior of soil cylinder containing a central sand drain. The vertical load on the model ground was applied by dead weights on a level hanger.

\section{NUMERICAL ANAYSIS}

The performance of the composite ground (prior to column failure) was simulated using the PLAXIS 2D program and the simulations were compared with the test results to understand the consolidation mechanism of the composite ground and to understand the role of area ratio, $a$ on the consolidation behavior. The finite element mesh was composed of 15-nodes triangular elements (vide Figure 2). The load was applied by step loading; the next loading was applied after the consolidation that was caused by the previous loading was complete. The applied load was $0,20,40$ and $60 \mathrm{kPa}$. Table 1 shows the model parameters for the surrounding clay and the soil-cement column. All the model parameters were obtained from the conventional laboratory tests. Overall, the numerical simulations are comparable with the test results.

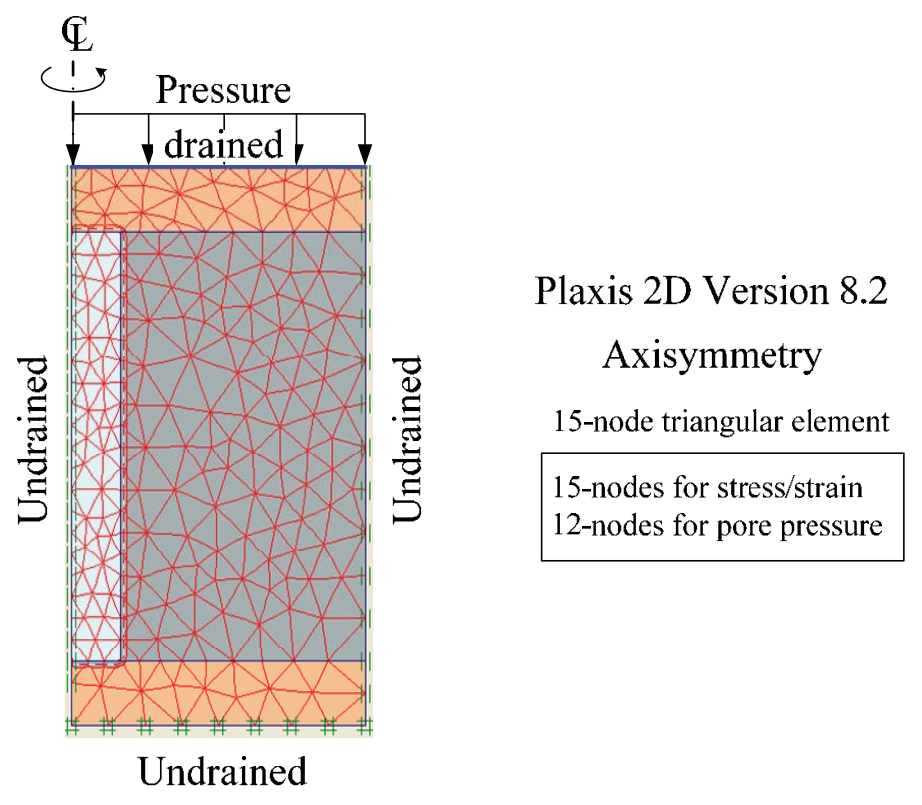

Figure 2. Finite element model for the model composite ground. 
Table 1. Model parameters for the composite ground.

\begin{tabular}{|c|c|c|c|c|}
\hline Soil & Sand & Bangkok clay & Soil-cement column & Unit \\
\hline Model & Mohr-Coulomb & Soft Soil & Mohr-Coulomb & - \\
\hline$\gamma_{d r y}$ & 17 & 16 & $\begin{array}{l}13(\mathrm{C}=20 \%) \\
14(\mathrm{C}=40 \%)\end{array}$ & $\mathrm{kN} / \mathrm{m}^{3}$ \\
\hline$\gamma_{\text {sat }}$ & 20 & 18 & $\begin{array}{l}13(\mathrm{C}=20 \%) \\
14(\mathrm{C}=40 \%)\end{array}$ & $\mathrm{kN} / \mathrm{m}^{3}$ \\
\hline$k_{v}$ & $3.43 \times 10^{-4}$ & $1.0 \times 10^{-7}$ & $5.0 \times 10^{-6}$ & $\mathrm{~m} / \mathrm{min}$ \\
\hline$k_{h}$ & $3.43 \times 10^{-4}$ & $1.0 \times 10^{-7}$ & $5.0 \times 10^{-6}$ & $\mathrm{~m} / \mathrm{min}$ \\
\hline$E^{\prime}$ & $\begin{array}{c}13,000 \text { (Top) } \\
52,000 \text { (Bottom) }\end{array}$ & - & $\begin{array}{l}112,000(\mathrm{C}=20 \%) \\
120,000(\mathrm{C}=40 \%)\end{array}$ & $\mathrm{kPa}$ \\
\hline$v^{\prime}$ & 0.3 & 0.3 & 0.3 & - \\
\hline$\lambda^{*}$ & - & 0.095 & - & - \\
\hline$\kappa^{*}$ & - & 0.0095 & - & - \\
\hline$c^{\prime}$ & 1 & 1 & 600 & $\mathrm{kPa}$ \\
\hline$\phi^{\prime}$ & 37 & 21 & 25 & degrees \\
\hline
\end{tabular}
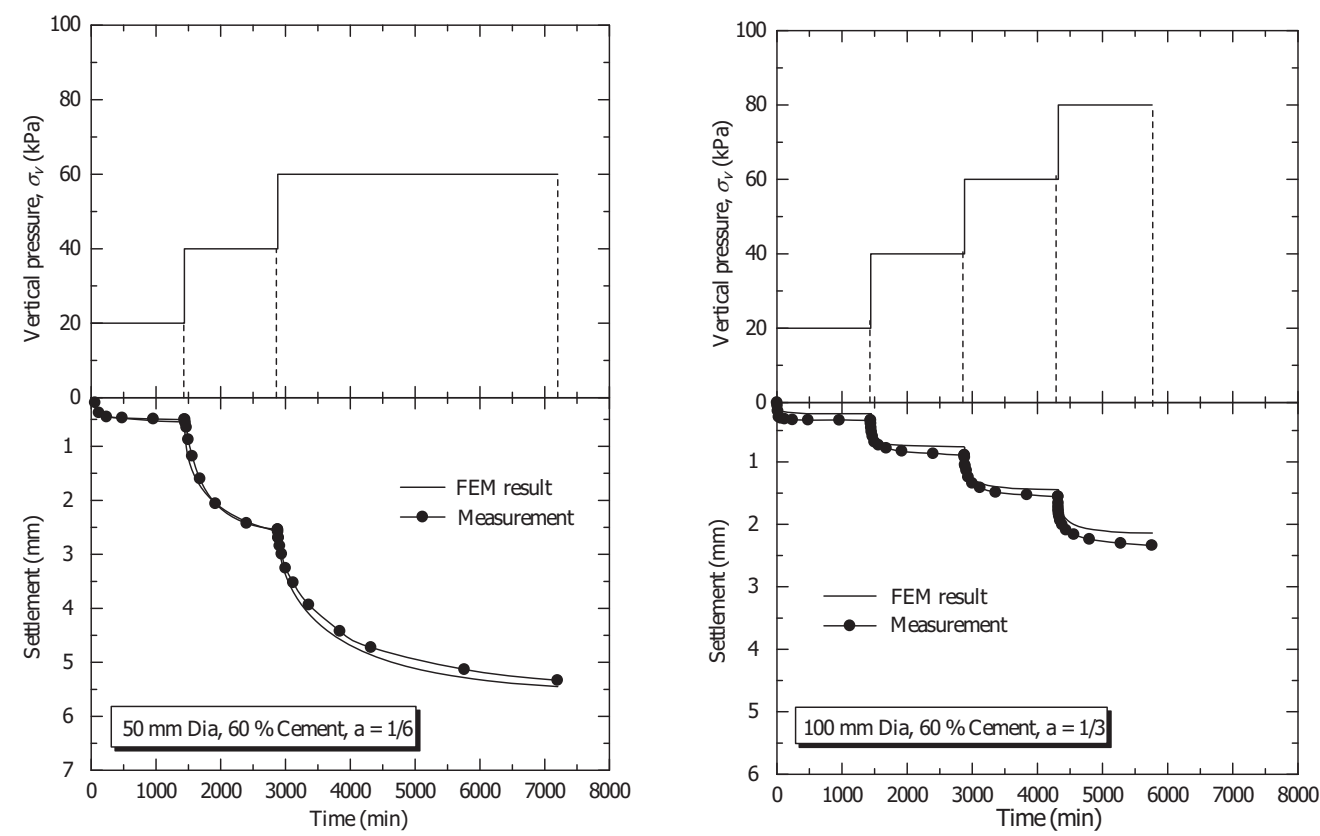

Figure 3. Comparison between simulated and measured settlement with time for different area ratios and cement contents.

Figure 3 shows the comparison between the simulated and measured settlements versus time for different area ratios, $a$. Both the settlement and rate of consolidation are governed by $a$. The composite ground with a high $a$ value exhibits low settlement and a high rate of consolidation. Figure 4 depicts the change in the excess pore pressure with radial distance at different consolidation times for the vertical stress increased from $20 \mathrm{kPa}$ to $40 \mathrm{kPa}$. The excess pore pressures in the soil- 
cement column dissipate more quickly than those in the surrounding clay only at the top of the composite ground; the excess pore pressures in both the soil-cement column and the surrounding clay at the same consolidation time are practically the same for deeper improvement depths.
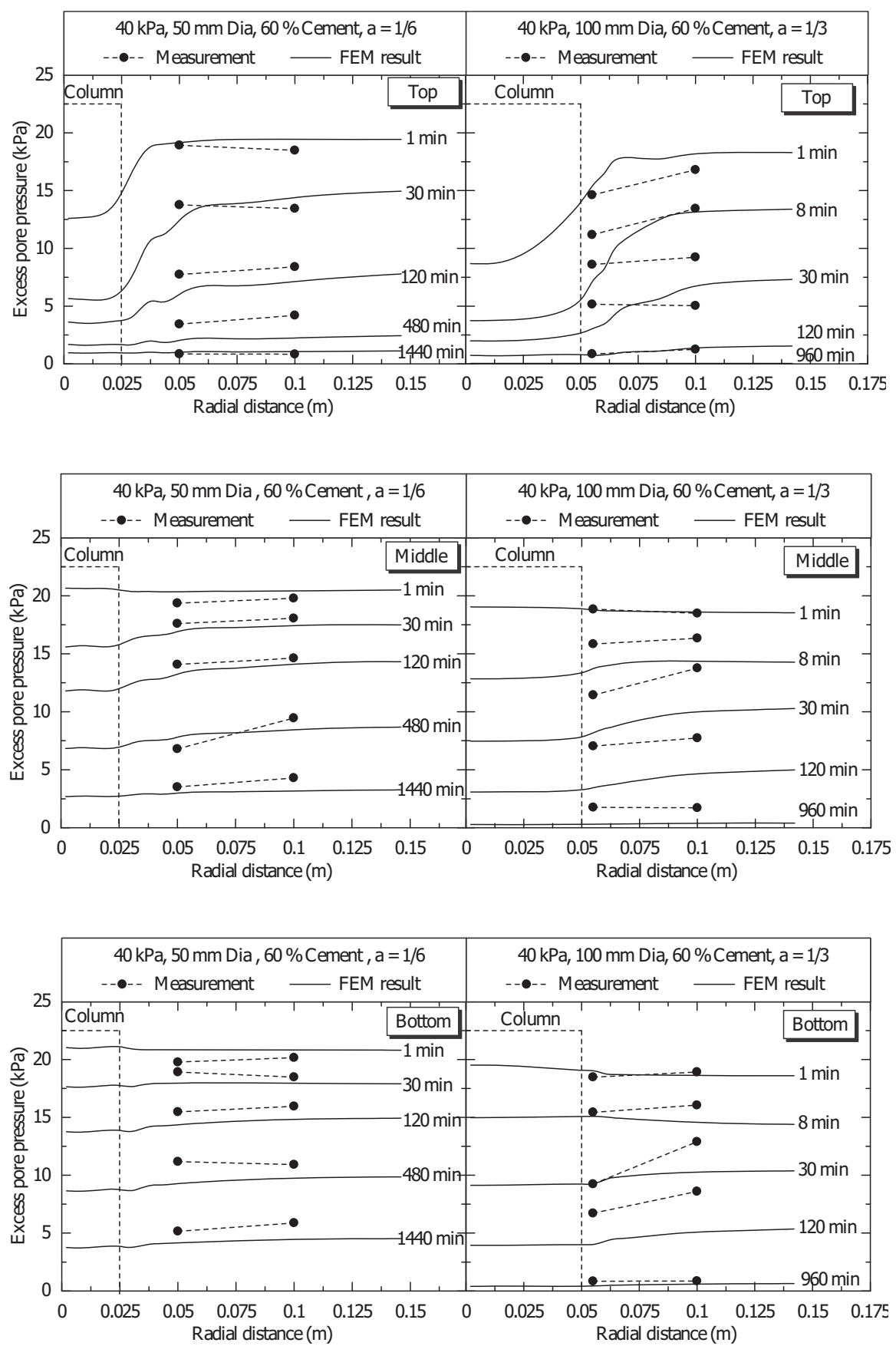

Figure 4. Relationship between simulated excess pore pressure and radial distance at different times and area ratios. 
As the area ratio increases, the stiffness/composite area and the yield stress of the composite ground increases. Consequently, the rate of consolidation increases and final settlement decreases for a given applied load. The yield stress of the composite ground can be determined in the same way as that of the soft clay in conventional consolidation test.

Figure 5 shows the typical relationship between the excess pore pressure and depth at different consolidation times. The consolidation behavior of the surrounding clay for the points near and far away from the soil-cement column (at 5 and $10 \mathrm{~cm}$ from the column) is similar to that of the clay deposit without soil-cement column. The maximum excess pore pressure is at the bottom and decreases with consolidation time. The rate of consolidation of the soft clay (no column) is slower and mainly dependent upon the coefficient of permeability. The soil-cement column enhances overall stiffness of the composite ground and hence the coefficient of consolidation. The composite coefficient of consolidation $\left(c_{v}=\frac{k}{\gamma_{w} m_{v}}\right)$ increases due to the increase in $m_{v}$, even though the permeability of both the surrounding clay and the column are almost the same.

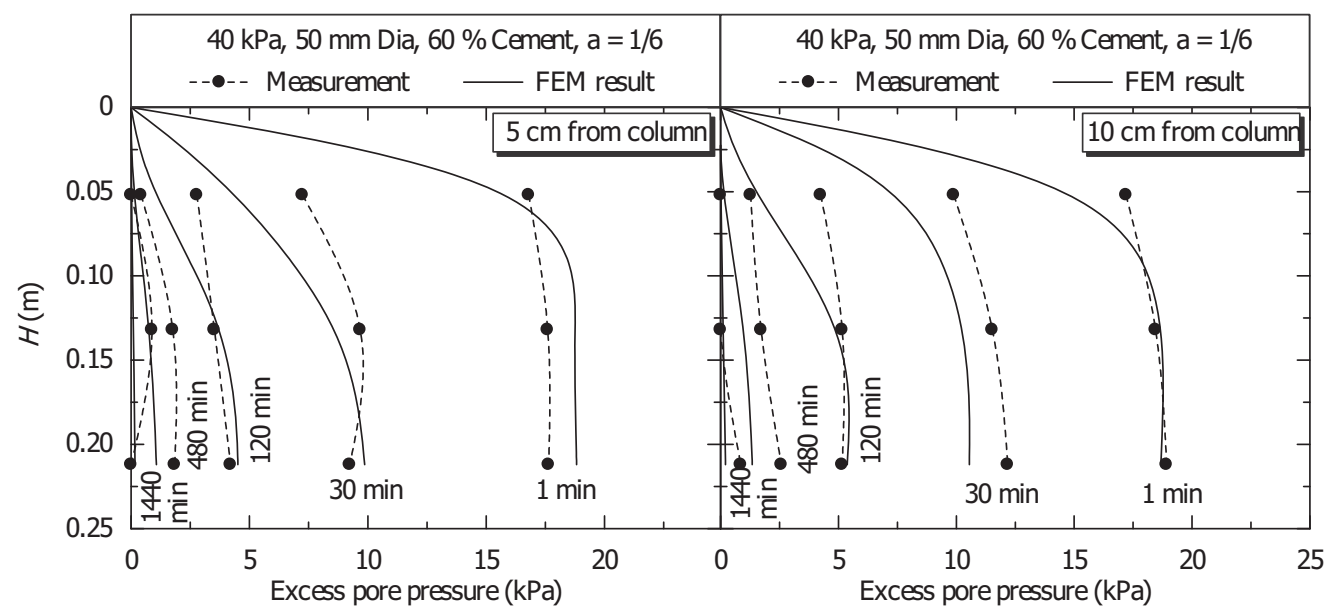

Figure 5. Relationship between excess pore pressure and depth at different consolidation times for $a=1 / 6$.

\section{CONCLUSIONS}

This paper presents the numerical simulation of the consolidation behavior of composite ground. The coefficients of permeability of the soil-cement column and surrounding clay are practically the same; therefore the soil-cement column does not act as the drain. Because the soil-cement column enhances the yield stress and stiffness of the composite ground, the composite ground is in an over-consolidated state under the applied vertical applied stresses. At this state, the rate of consolidation is rapid due to a high coefficient of consolidation. The area ratio, $a$, significantly affects the consolidation behavior of the composite ground. The composite ground 
with a high $a$ value has a high load capacity and carries low stress. Thus, the settlement is small and consolidation is rapid.

\section{ACKNOWLEDGEMENTS}

This work was supported by the Higher Education Research Promotion University project of Thailand, Office of Higher Education Commission. The financial support and facilities provided from the Suranaree University of Technology are appreciated.

\section{REFERENCES}

Barron, R.A. (1948). "Consolidation of fine grained soils by drain wells.", Transaction ASCE, 113, 718.

Horpibulsuk, S., Bergado, D. T., and Lorenzo, G. A. (2004a). "Compressibility of cement admixed clays at high water content." Geotechnique, 54(2), 151-154.

Horpibulsuk, S., Miura, N., and Bergado, D.T. (2004b). "Undrained shear behavior of cement admixed clay at high water content." Journal of Geotechnical and Geoenvironmental Engineering, ASCE, 130(10), 1096-1105.

Horpibulsuk, S., Miura, N., Koga, H., and Nagaraj, T. S. (2004c). "Analysis of strength development in deep mixing - A field study." Ground Improvement Journal, 8(2), 59-68.

Horpibulsuk, S., Miura, N., and Nagaraj, T. S. (2005). "Clay-water/cement ratio identity of cement admixed soft clay." Journal of Geotechnical and Geoenvironmental Engineering, ASCE, 131(2), 187-192.

Horpibulsuk, S., Liu, M. D., Liyanapathirana, D. S., and Suebsuk, J. (2010). "Behavior of cemented clay simulated via the theoretical framework of the Structured Cam Clay model." Computers and Geotechnics, 37, 1-9.

Horpibulsuk, S., Rachan, R., and Suddeepong, A. (2011a). "Assessment of strength development in blended cement admixed Bangkok clay." Construction and Building Materials, 25(4), 1521-1531.

Horpibulsuk, S., Rachan, R., Suddeepong, A., and Chinkulkijniwat, A. (2011b), "Strength development in cement admixed Bangkok clay: laboratory and field investigations." Soils and Foundations, 51(2), 239-251.

Kamaluddin, M. and Balasubramaniam, A.S. (1995). "Overconsolidated behavior of cement treated soft clay." Proceedings of $10^{\text {th }}$ Asian Regional Conference on Soil Mechanics and Foundation Engineering, Thailand, 407-412.

Kasama, K., Ochiai, H., and Yasufuku, N. (2000). "On the stress-strain behaviour of lightly cemented clay based on an extended critical state concept." Soils and Foundations, 40(5), 37-47.

Kawasaki, T., Niina, A., Saitoh, S., Suzuki, Y., and Honjo, Y. (1981), "Deep mixing method using cement hardening agent." Proceedings of $10^{\text {th }}$ International Conference on Soil Mechanics and Foundation Engineering, Stockholm, 721724. 
Miura, N., Horpibulsuk, S., and Nagaraj, T.S. (2001). "Engineering behavior of cement stabilized clay at high water content." Soils and Foundations, 41(5), $33-45$.

Nishida, K., Koga, Y. and Miura, N. (1996). "Energy consideration of the dry jet mixing method." Proceedings of $2^{\text {nd }}$ International Conference on Ground Improvement Geosystems, IS-Tokyo '96, 1, 643-748.

Probaha, A., Raybaut, J. L., and Nicholson, P. (2001). "State of the art in construction aspects of deep mixing technology." Ground Improvement, 5(3), 123-140.

Suebsuk, J., Horpibulsuk, S., and Liu, M. D. (2010). "Modified Structured Cam Clay: A constitutive model for destructured, naturally structured and artificially structured clays." Computers and Geotechnics, 37, 956-968.

Suebsuk, J., Horpibulsuk, S., and Liu, M. D. (2011). "A critical state model for overconsolidated structured clays." Computers and Geotechnics, 38, 648-658.

Yin, J.H., and Fang, Z. (2006). "Physical modelling of consolidation behaviour of a composite foundation consisting of a cement-mixed soil column and untreated soft marine clay." Geotechnique, 56(1), 63-68. 